\title{
Pseudo-Bartter as an initial presentation of cystic fibrosis. A case report and review of the literature
}

\author{
M.A. Marah
}

\section{Introduction}

Cystic fibrosis (CF) is an autosomal recessive condition caused by the mutation of the cystic fibrosis transmembrane regulator gene (CFTR) on chromosome 7. Although it primarily affects the respiratory and gastrointestinal tracts, it can also involve other organs. It may also cause electrolyte and acid base disturbances, rarely the mode of presentation. This can result in difficulty in making an early diagnosis in the absence of other characteristic clinical features.

We report here such a case which presented in infancy.

\section{Case report}

A 6-month old Yemeni infant presented with an 8-day history of diarrhoea and vomiting. He was born at full term with an uneventful prenatal, perinatal and postnatal history. His parents, who are first-degree cousins, and his 4-year-old sister were healthy.

On presentation, he was febrile and had moderate dehydration $(<10 \%)$. His weight was $7.8 \mathrm{~kg}$ (just above the 5 th percentile), length $69 \mathrm{~cm}$ (on the 10th percentile) and head circumference 43.8 $\mathrm{cm}$ (on the 5th percentile). His blood pressure fluctuated between $70 / 50$ $\mathrm{mmHg}$ and $100 / 80 \mathrm{mmHg}$. The rest of his examination was unremarkable.

Analysis of serum electrolytes gave the following results: sodium $124 \mathrm{mmol} / \mathrm{L}$, potassium $4 \mathrm{mmol} / \mathrm{L}$, chloride $84 \mathrm{mmol} / \mathrm{L}$, bicarbonate 29 $\mathrm{mmol} / \mathrm{L}$ and creatinine $0.4 \mathrm{mg} / \mathrm{dL}$. He required intravenous fluid therapy and was discharged after correction of his biochemical abnormalities.

He was readmitted 5 more times over a 2-year period with episodes of diarrhoea and vomiting associated with similar biochemical abnormalities (Table 1). He never had significant respiratory problems throughout that period, The possibility of Bartter syndrome was raised, but the diagnosis was dismissed as his blood pressure was initially high, urinary chloride excretion was low with only slightly elevated levels of serum renin $(320 \mathrm{ng} / \mathrm{dL}$ at rest and standing) and aldosterone (195 ng/dL at rest and $206 \mathrm{ng} / \mathrm{dL}$ while standing).
Further evaluation, around the age of 1 year and while he was clinically stable, revealed a thriving child with the following serum biochemical results: sodium $133 \mathrm{mmol} / \mathrm{L}$, potassium $3.4 \mathrm{mmol} / \mathrm{L}$, chloride $100 \mathrm{mmol} / \mathrm{L}$ and bicarbonate $22 \mathrm{mmol} / \mathrm{L}$. The serum levels of aldosterone $(99 \mathrm{ng} / \mathrm{dL})$ and renin $(84 \mathrm{ng} / \mathrm{dL}$ ) were normal, so was urinary chloride excretion $(20 \mathrm{mg} / \mathrm{dL})$ but the fractional excretion of potassium was elevated at $67 \%$. Hyponatraemia was interpreted as being secondary to prolonged diarrhoea and vomiting, hypokalaemia to stool losses, metabolic alkalosis to extra cellular compartment contraction and the initial but transient rise in blood pressure to secondary hyperaldosteronism. Tubulopathy was excluded in view of the absence

\begin{tabular}{|c|c|c|c|c|c|}
\hline \multirow[t]{2}{*}{ Biochemical measure } & \multicolumn{5}{|c|}{ Date } \\
\hline & 24/4/99 & $09 / 5 / 99$ & 25/9/99 & 04/7/99 & 03/9/01 \\
\hline Plasma Na (mEq/L) & 117 & 131 & 125 & 127 & 126 \\
\hline Plasma Cl (mEq/L) & 84 & 88 & 85 & 82 & 89 \\
\hline Serum K (mEq/L) & 3.1 & 3 & 4 & 3.2 & 2.7 \\
\hline Plasma $\mathrm{HCO}_{3}(\mathrm{mEq} / \mathrm{L})$ & 30 & 28 & 28 & 28 & 29 \\
\hline Blood Urea (mg/dL) & 8 & 6 & 25 & 34 & 23 \\
\hline Serum Creatinine $(\mathrm{mg} / \mathrm{dL})$ & - & 0.4 & 0.6 & 0.7 & 0.9 \\
\hline Plasma pH & 7.54 & - & 7.5 & 7.55 & 7.56 \\
\hline $\mathrm{HCO}_{3}$ & 31 & - & 29 & 30.3 & 31 \\
\hline Base excess & 4 & - & 2 & 4 & 5 \\
\hline Urinary $\mathrm{Na}(\mathrm{mEq} / \mathrm{L})$ & - & 10 & $<10$ & - & $<10$ \\
\hline Urinary $\mathrm{K}(\mathrm{mEq} / \mathrm{L})$ & - & 43 & - & - & 54.7 \\
\hline Urinary $\mathrm{Cl}(\mathrm{mEq} / \mathrm{L})$ & - & $<10$ & $<10$ & - & $<10$ \\
\hline Serum aldosterone $(\mathrm{ng} / \mathrm{dL})$ & 99.2 & - & - & - & - \\
\hline Serum renin $(\mathrm{ng} / \mathrm{dL})$ & 84 & - & - & - & - \\
\hline
\end{tabular}


of hypercalciuria, hypocalcaemia, hypomagnesaemia, hypermagnesuria or significant hypokalaemia. The patient was discharged on sodium chloride and potassium chloride supplementation.

After being lost to follow-up for several years, he was seen again at the age of 8 years when he presented with sever gastroenteritis, hypovolaemic shock and chest infection. His height and weight were below the $3 \mathrm{rd}$ percentile, temperature was $38.7^{\circ} \mathrm{C}$, heart rate $98 / \mathrm{min}$, respiratory rate $30 / \mathrm{min}$, blood pressure $70 / 50 \mathrm{mmHg}, \mathrm{O}_{2}$ saturation $88 \%$ in room air and capillary refill 4 seconds. He had marked finger and toe clubbing, with bilateral crepitations heard on auscultation.

He underwent fluid resuscitation and investigations showed the following results: serum sodium $128 \mathrm{mmol} / \mathrm{L}$, chloride $76 \mathrm{mmol} / \mathrm{L}$, potassium $3.3 \mathrm{mmol} / \mathrm{L}$, bicarbonate $28 \mathrm{mmol} / \mathrm{L}$, anion gap $15.6 \mathrm{mmol} / \mathrm{L}$, urea $35 \mathrm{mg} / \mathrm{dL}$, creatinine $1.3 \mathrm{mg} /$ $\mathrm{dL}$, calcium $10.5 \mathrm{mg} / \mathrm{dL}$, phosphorus $7.6 \mathrm{mg} / \mathrm{dL}$ and magnesium $2.3 \mathrm{mg} /$ dL. Blood gas results were: $\mathrm{pH} 7.51$, pCO2 $48.4 \mathrm{mmHg}, \mathrm{pO} 265 \mathrm{mmHg}$, base excess $6.1 \mathrm{mmol} / \mathrm{L}$, bicarbonate $31.6 \mathrm{mmol} / \mathrm{L}$. Urinary electrolytes results were: sodium $<10 \mathrm{mmol} / \mathrm{L}$, chloride $<15 \mathrm{mmol} / \mathrm{L}$, potassium 117 $\mathrm{mmol} / \mathrm{L}$, calcium excretion $<2 \mathrm{mg} /$ day and magnesium excretion $2.3 \mathrm{mg} /$ day. Bilateral streaky infiltrates were seen on chest radiography. Sputum culture grew Pseudomonas aeruginosa and blood and urine cultures revealed no bacterial growth. Fluid therapy led to gradual biochemical correction over 3 days.

The suspected diagnosis of cystic fibrosis was confirmed with a sweat chloride level of $120 \mathrm{mmol} / \mathrm{L}$ and homozygozity for the Delta F 508 gene on genetic studies. The child was started on standard CF therapy. He is currently doing well regarding weight gain and his blood chemistry remains normal.

\section{Discussion}

CF is an inherited disorder affecting most organ,s especially the exocrine glands. It is associated with a large number of mutations affecting the chloride channel, the commonest being mutation of the delta F508 on chromosome 7. The manifestation of the disease can appear at birth or later in the life according to the type of mutation, which also predicts the severity of the disease [1]. The most common systems affected are respiratory (where the typical presentation includes recurrent pneumonia and obstructive lung disease) and digestive (secondary to pancreatic insufficiency) leading to growth failure [1]. Other manifestations include renal agenesis [2] and absence of vas deferens $[1,2]$. Uncommonly, it can present as an acid-base and electrolyte imbalance, such as hypokalaemia, hyponatraemia and metabolic alkalosis.

Most children with CF presenting as hypoelectrolytaemia and metabolic alkalosis (so-called pseudo-Bartter) were under the age of 6 months $[3,4]$. Multiple inter-related factors have been incriminated in its pathophysiology. Normally, with the cystic fibrosis transmembrane regulator (CFTR) gene regulating sweat production, normal sweat glands produce iso-osmotic primary sweat, partly by chloride secretion across the apical CFTR [5]. The water-impermeable sweat duct reabsorbs sodium chloride transcellularly, leading to the excretion of hypotonic sweat, enabling the body to regulate its temperature with minimal loss of electrolytes [5]. The volume of sweat in CF patient is different from that in healthy people [6]. Although the production of primary sweat is relatively normal in $\mathrm{CF}$ patients [5], the dysfunctional CFTR in the sweat duct results in excessive sodium and chloride loss in the final sweat $[5,6]$. This loss in sodium chloride is more marked in hot weather where the rate of sweat production may reach up to 2 litres/hour [5-7], leading to massive sodium chloride loss which results in significant extracellular volume contraction and secondary hyperaldosteronism. This hyperaldosteronism will lead to increased potassium losses both in the sweat and the urine, resulting in hypokalaemia [3,8-14].

The pathophysiology of metabolic alkalosis includes: volume depletion leading to a relatively high bicarbonate level in the contracted extracellular volume (haemoconcentration) [3,8,9,15], and low extracellular chloride leading to increased reabsorption of bicarbonate to replace the lost extracellular anions (chloride and bicarbonate) [3,9]. In addition, the extracellular volume depletion leads to decreased filtered load of bicarbonate in the urine due to decreased Glomerular filtration rate (GFR) $[3,8]$ and the hypokalaemia itself can maintain and generate metabolic alkalosis $[3,8,15,16]$. The effect of these electrolyte losses is the activation of the renin-angiotensin system and stimulation of sodium cation (hydrogen, potassium) exchange, with resulting alkalosis and potassium depletion. Although hyperaldosteronism without distal sodium delivery will not cause alkalosis, an increase in mineralocorticoid with distal proton delivery would, as in the case of Bartter syndrome and chronic diuretic use. Studies have shown that some changes in renal sodium handling [17] and free water clearance [18] occurs in CF patients. Furthermore, the CFTR (or CFTR-like) gene or protein has been located in the proximal tubules of rabbits [19,20], rats [21], mice [20] and also in human distal tubules [22]. Thus, a volume-depleted CF patient can still maintain distal sodium delivery due to dysfunctional CFTR.

Gastrointestinal losses act as contributory factors, accentuating an underlying salt depletion and metabolic alkalosis. In all CF infants with acute or chronic fluid and electrolyte losses with sweating, their metabolic abnormalities and condition are aggravated by acute intercurrent episodes of vomiting, 
diarrhoea, or respiratory symptoms $[3,7,10]$. These intercurrent illness acts as a precipitating event aggravating the underlying metabolic alkalosis and hypoelectrolytaemia. In addition, infants with CF are prone to develop episodes of hyponatraemic hypochloraemic dehydration with metabolic alkalosis, due to excess salt loss with sweating, especially in regions with a hot, dry climate, during the warmer months $[3,7,10]$. Breastfed infants are more prone to have such electrolyte derangement especially in hot weather due to low salt content in the breast milk [10].

In our patient, the volume depletion was most likely secondary to many factors including: hot climate, episodes of gastroenteritis, recurrent vomiting and intercurrent infections. It led to contraction alkalosis due to the relative increase in serum bicarbonate concentration and decrease in filter load of bicarbonate secondary to decreased GFR. This volume depletion led to activation of the renin-angiotensin system and secondary hyperaldosteronism (Table 1) with enhanced urinary and sweat potassium excretion. This resulted in hypokalaemia, which by itself could aggravate and maintain the metabolic alkalosis.

Hypochloraemic metabolic alkalosis with increased serum aldosterone and renin levels occurs in both Bartter and in CF (pseudo-Bartter) $[12,13,15]$ syndrome. The main difference is that urinary chloride losses in Bartter syndrome are high, while they are low in CF (with elevated sweat chloride losses).

When faced with a child with hypochloraemic hypokalaemic metabolic alkalosis, causes other than Bartter syndrome need also to be considered. They includepersistentvomiting (as in pyloric stenosis), congenital chloride-losing diarrhoea, Gittelman syndrome, diuretic use and primary hyperaldosteronism $[1,3,8,10,15]$. A practical approach to deal with hypochloraemic metabolic alkalosis is suggested. First, urinary chloride level should be measured: if very high, Bartter syndrome is very likely. If it is not elevated, other non-urinary chloride losses, such as stool losses (congenital chloride diarrhoea or laxative abuse) or excessive losses in sweat (CF) should be considered.

\section{Conclusion}

When confronted with hypochloraemic hypokalaemic metabolic alkalosis, the possibility of CF must always be considered, even in the absence of characteristics clinical features.

\section{References}

1. Kliegman RM, Behrman RE, Jenson HB, eds. Nelson textbook of pediatrics, 17th ed. Burlington Massachusetts, 2003.

2. Gervais R et al. High frequency of the R117H cystic fibrosis mutation in patients with congenital absence of the vas deferens. New England journal of medicine, 1993, 328:446-7.

3. Bates CM, Baum M, Quigley R. Cystic fibrosis presenting with hypokalemia and metabolic alkalosis in a previously healthy adolescent. Journal of the American Society of Nephrology, 1997, 8:352-5.

4. Sojo A et al. Chloride deficiency as a presentation or complication of cystic fibrosis. European journal of paediatrics, 1994, 153:825-8.

5. Quinton PM. Physiology of sweat secretion. Kidney international supplement, 1987, 21:S102-8.

6. Bijman J. Transport processes in the eccrine sweat gland. Kidney international supplement, 1987, 21:S109-12.

7. Ruddy R, Anolik R, Scanlin TF. Hypoelectrolytemia as a presentation and complication of cystic fibrosis. Clinical pediatrics, 1982, 21(6):367-9.

8. Ozçelik $U$ et al. Sodium chloride deficiency in cystic fibrosis patients. European journal of pediatrics, 1994, 153:829-31.

9. Halperin ML, Goldstein MB, Halperin ML. Fluid, electrolyte and acid-base physiology: a problem-based approach, 3rd ed. Philadelphia, WB Saunders, 1999.

10. Fustik $\mathrm{C}$ et al. Metabolic alkalosis with hypoelectrolytemia in infants with cystic fibrosis. Pediatrics international, 2002, 44:289-92.

11. Oztürk Y, Soylu OB, Arslan N. Prevalence and clinical features of cystic fibrosis with pseudo-Bartter syndrome. Annals of tropical paediatrics, 2006, 26:155.

12. Sauter R, Will M, Helwig H. Schwere Hyponatriamie als diagnoseweisendes Symptom der cystischen Fibrose [Severe hy- ponatremia as diagnostic symptom of cystic fibrosis]. Klinische pädiatrie, 1997, 209:361-3.

13. Yalçin E et al. Clinical features and treatment approaches in cystic fibrosis with pseudo-Bartter syndrome. Annals of tropical pediatrics, 2005, 25:119-24.

14. Forsyth JS, Gillies DR, Wilson SG. Cystic fibrosis presenting with chronic electrolyte depletion, metabolic alkalosis and hyperaldosteronism. Scottish medical journal, 1982, 27:333-5.

15. Kennedy JD et al. Pseudo-Bartter's syndrome in cystic fibrosis. Archives of disease in childhood, 1990, 65:786-7.

16. Galla JH, Bonduris DN, Luke RG. Effects of chloride and extracellular fluid volume on bicarbonate reabsorption along the nephron in metabolic alkalosis in the rat. Reassessment of the classical hypothesis of the pathogenesis of metabolic alkalosis. Journal of clinical investigation, 1987, 80:41-50.

17. Stenvinkel $\mathrm{P}$ et al. Decreased renal clearance of sodium in cystic fibrosis. Acta paediatrica Scandinavica, 1991, 80:194-8.

18. Donckerwolcke RA et al. Impaired diluting segment chloride reabsorption in patients with cystic fibrosis. Child nephrology and urology, 1992, 12:186-91.

19. Seki $\mathrm{G}$ et al. Activation of the basolateral $\mathrm{Cl}$ conductance by CAMP in rabbit renal proximal tubule S3 segments. Pflügers archiv, 1995, 430:88-95.

20. Todd-Turla KM et al. CFTR expression in cortical collecting duct cell. American journal of physiology, 1996, 270:F237-44.

21. Husted RF et al. Anion secretion by the inner medullary collecting duct. Evidence for involvement of the cystic fibrosis transmembrane conductance regulator. Journal of clinical investigation, 1995, 95:644-50.

22. Davidow $\mathrm{CJ}$ et al. The cystic fibrosis transmembrane conductance regulator mediates transepithelial fluid secretion by human autosomal dominant polycystic kidney disease epithelium in vitro. Kidney international, 1996, 50:208-18. 